\title{
Elementary Exploration on the Embedded Intelligent Accounting Information System
}

\author{
Lixia Sun \\ SIAS International academy of Zhengzhou University, No.168, Renmin Road, Xinzheng City, Henan, \\ PR. China
}

\begin{abstract}
In the face of increasingly fierce competition and challenge, more and more corporations realize that what if the decisions could not be rapidly and accurately made or the potential business problems could not be promptly found, that would mean a great failure; Seizing the benefit is to find potential rules that our competitors have not found yet and rapidly and accurately make decisions. Hence, the corporations turn their sights into the financial intelligence, namely the assistant technology of financial information management. Financial intelligent system is the product that conforms to the economic development and change, which is one of technological means and methods that could improve the market competitiveness of enterprises.
\end{abstract}

Keywords: embedded intelligent; accounting information system; financial management.

\section{Accounting information system is in need of embedding financial intelligence}

Financial intelligent system is to formalize the financial management theory and import data into the data warehouse by means of intelligent match ways or regard the existing data in the data warehouse as the analytic targets to manage them on the basis of financial management models and by means of taking advantage of the high-speed and accurate computing power of the computers thus to rapidly get the management diagnosis report of the enterprises and formalize the operating decision suggestions. Financial intelligent system is the product that conforms to the economic development and change. Although the theory and practice of financial intelligent system are just starting, it gathers the international advanced financial management theory and thorough financial management system, which is one of technological means and methods that could improve the market competitiveness of enterprises. Financial intelligent system can classify the mass information of enterprises, proceed multi-dimension analysis on the management and financial data on the basis of the requirements, formalize intelligent multi-dimension perspective analysis charts, and provide the enterprises for more timely, accurate and comprehensive financial management information, and promote the financial management to play the role of improving work efficiency and assisting to make the decisions. Therefore, financial intelligent system is a favorable tool to deepen information and apply the achievements for the enterprises. And it has vast potential for future development in the accounting information system of the enterprises.

At present, financial intelligent system has not been widely popularized yet. Enterprises usually lays emphasis on the business accounting and makes light of financial evaluation and analysis. The enterprises usually adopt the accounting information system to analyze and manage the financial data firstly and then chose the financial data they need and then export them into the financial intelligent system for the sake of postmortem analysis. The enterprises merely regard the financial intelligent system as a system that only processes the data, which never gives play to the functions of financial intelligent system that can provide timely and comprehensive management information and wastes a mass of enterprise resources. In the meanwhile, the key point of accounting information system is to record and control the process of proceeding business. In other word, the accounting information system is a transaction processing system but with inborn defect in the aspect of statement analysis and management. For instance, the accounting information system needs a mass of manual processing; it is hard to realize multi-dimension analysis flexibly realize the analysis which spans two years with the accounting information system; the graph functions of the accounting information system is weaker so that it is hard to present data in the way of graphs; In the accounting information system, it is hard to understand the information in the decision-making thinking way. Therefore, most 
enterprises merely regard the system as a electronic accounting tool. It is a must to use the embedded technology for the sake of fully realizing the most optimal functions of financial intelligence and accounting information system. That embedding the financial intelligence into the accounting information system can realize the combining and development of both of them.

\section{Ways of embedding financial intelligent system into the accounting information system}

It is the future development trends to embed the financial intelligence into the accounting information system. The embedding ways mainly include three aspects.

\subsection{The embedment of Pivot table in the statement analysis system}

Pivot table is a kind of interactive table that can quickly gather mass of data and set up cross tabulation. Essentially, pivot table is one of tools in Excel tool box. If assimilate the pivot table report to a physical tool that can be held in hand, then the kaleidoscope would be the most precise one can represent the pivot table because many ways can be used to look at the objects by means of kaleidoscope. When checking the data sets via data table, it is possible to examine some details in data which never be found before; Otherwise, the pivot table can be spun for the sake of checking data from different perspectives. Now that the pivot table has so almighty functions, it should be fully applied into the accounting information system. And the functions of the pivot table should be embedded into the subsystem of the report to realize the perspective analysis for data.

If the present accounting information system wants to proceed statistical analysis of data from the perspective of group headquarters, it needs to export various statistical statements from the systems of each organization of the group, anew proceed various classification and statistics on the basis of codes, and arrange the data to be the stationary die plate that the headquarters need. When gathered in the headquarters, the data are combined and calculated by specially-assigned persons of each department. In other word, the whole process causes mass of manual work.

After embedding the financial intelligence into the accounting information system, accounting personnel only need to collect various reports into one EXCEL table, then use the mouse to drag the field from one zone to another zone. Few seconds later, a summarizing and classified interactive pivot table can be established. After the functions of the pivot table are embedded into the EXCEL table, the powerful features of statement analysis will lie in the functions of classification and gathering the data into different sections. Then, when check data correlated to relevant sections, users may interactively spin and drag and drop the field in the table, classify and gather the data from different angles, dynamically modify the perspective data and recalculate the total for the sake of adjusting to present table view. The accounting personnel not only can establish the tabulated form of data but also establish multidimensional perspective drawing of data to quickly, accurately and scientifically understand the meaning of data and help the enterprises make effective decisions. With regard to those worksheets which are numerous, complicated and recorded by the form of journal account, the system can recombine the worksheets and add new algorithm to upward and downward drill and finally realize the drill layer by layer until the data are listed in details and the inherent laws emerged, and then the problems will be no place to hide. The accounting personnel improve the analysis ability and insight for data, which will transform the business data into enterprise resources thus realize the transformation that is about from data to information and then to intelligence and insight.

Secondly, the embedding of visualization technology in the information display layer. Visualization technology refer to taking advantage of computer graphics and image processing techniques to transform the data into graphs or images to be displayed on the screen and proceed interactive processing theories, methods and technologies. The basic idea is to adopt the computer graphics, image processing techniques and interactive techniques to convert the abstract original data information in the database to geometric figure and pattern information and make them display on the screen, and help the decision maker to proceed the observation and analysis at different dimensions, thus to fully take advantage of the mass data information and help the decision maker get the most valuable management and decision information. In short, the embedding of visualization technology 
is to analyze the mass abstract data, make the plane data to be three-dimensional and improve the presentation effect of data.

With regard to the display layers of accounting information such as data processing, inquiry and application, the embedding of visualization technology may provide abundant and changeable to meet the requirements reports and charts, improve the intelligent display effect of accounting information, and make the data easier to understand and express. By means of visualization functions, the accounting personnel only need to pull, drag and WYSIWYG the interface(namely what you see is what you have got), then can easily establish and combine the interface of the charts, patterns, pictures, texts and tables of any kinds and intuitively present the data at the way of charts. What's more, the reports won't be rigid any more. It looks like an interactive picture of heating power, and all the results appear vividly on the interface. When you browse the reports, you could interactively use the reports at the same time. For instance, when you click one of the categories in the charts, the right chart will automatically display the details of this category, which could satisfy the individual requirements of decision makers. The display interface may be a simple search box which bases on the Web interface. The decision makers may browse and search the financial information by means of simple keywords, and it looks like that it is as easy as to browse the internet or the online shop; Multiple drop-down lists are convenient for the decision makers to proceed the combinational selection of financial indexes of all kinds and can satisfy the different demands of users; Multiple links may provide decision makers for the financial information of other enterprises in the same industry. The individual and friendly interface will provide the decision makers for the clear insights and help them make quick action and effect decisions.

Thirdly, the embedding of functions of cockpit of management in the decision-making system. In the face of middle and senior managers in enterprises, the cockpit of management bases on the ERP senior decision support system, intelligently analyzes on the abstracted business data by means of detailed target systems, translates the business data into analyzing information, and helps the management layer to make accurate and wise operating decisions. First of all, all the key performance indicators (KPI) correlated to the business operation can be displayed on the four walls of cockpit of management at the way of quantifiable graphs, and the walls with different colors will support the decision makers for targets with specialized information. There are six small screens of managing instrument panels on each wall, which can help the managers to interrelate the targets and analyze the them at lateral and longitudinal ways at anytime and anywhere, and to find other related information by means of further clicking and searching, and to make the most effective decisions within the shortest time. In the second place, the flight deck provides the analysis of profitability, operating ability, debt paying ability, developing ability, cash flow, investment and financial reports, realizes the inquiry of real-time information of enterprises, and helps the managers to timely master the present state of operation, state of profits composition and state of income of enterprises. What's more, the set-up real-time alarm system may provide the managers for performance evaluation and risk forewarning indexes, which helps to timely and effectively solve the present problems. The products of ERP have contained the functions of cockpit of management. The foreign ERP manufacturers embeds the financial intelligent functions into ERP products by means of purchasing the BI manufacturers. In 2003, Yongyou introduced the functions of cockpit of management into their products. In 2005, Jindie introduced the functions of cockpit of management into the products of K3.

The embedding of cockpit of management will make the analyzing and decision-making functions of accounting information system more conform to the requirements of management layer, gather all the information that managers of enterprises may care into one interface which contains alarm for the key operational indicators, daily report for the business, internal statements of enterprises of all kinds, external information document of enterprises of all kinds, and make the decision-making information gateway become the information working platform of enterprises managers. In the main interface of cockpit of management, managers may timely master present state of operation of enterprises, state of profits composition and state of income of enterprises, and cockpit of management can reflect the potential operating problems by means of the financial early-warning and warn the managers to adopt necessary measures. Deeply searching for all kinds of key data can help managers to deeply give an 
insight into the state of operation and precisely made further strategic decisions. This interface also provides the managers for the performance evaluation and risk early-warning targets, which helps to timely and effectively solve the problems.

\section{Conclusion}

Financial intelligence system is a useful tool for enterprise to deepen informationization, widely used in the accounting information system (AIS). The emergence of the embedded intelligent AIS can promote the efficiency of financial management of enterprises, help to make business decisions. The embedded intelligent AIS promotes the analysis-management mode of the financial system of the enterprises. According to the enterprise requirements for financial system and intelligent AIS characteristics, this paper embedded financial intelligence into the AIS by the following three methods: embedding PivotTable data into the Financial Report Analysis System; embedding visualization technology into information expression; embedding management cockpit into the decision making system. Embedded intelligent accounting information system embeds the Financial intelligence system into the AIS, promoting the blending and developing, realizing the optimization of intelligence financial system function.

\section{References}

[1] Jian Wang, Feng'e Sun, Shaowei Gao. Financial intelligence, are you ready? [J]. China Management Informationization, 2008, 15

[2] Dongli Zuo. Let the financial intelligence be the enterprise power [J]. China Food, 2006, 13.

[3] Bill Jelen, Michael Alexander, Pivot Table--Excel 2007 thorough analysis on PivotTable [J]. 2008,2

[4] Xinde Chen. Cockpit of management--New tool for the decision-making of the enterprises [J]. Management practice, 2003, 1.

[5] Jian Wang, Qi Liu, Shaowei Gao. The construction strategies for financial intelligence with low risk under the angle of view of Green IT [J]. Bulletin of Science and Technology, 2010, 2 